\title{
Preparation, evaluation and modification of PVDF-CTFE hydrophobic membrane for MD desalination application
}

\author{
Libing Zheng ${ }^{\text {a,b,c }}$, Jun Wang ${ }^{\text {a,d,e,* }}$, Jie Li ${ }^{\text {a,d }}$, Yong Zhang ${ }^{\text {a,d,e }}$, Kun Li ${ }^{\text {a,b }}$, Yuansong Wei ${ }^{\text {a,b,** }}$ \\ a State Key Laboratory of Environmental Aquatic Chemistry, Research Center for Eco-Environmental Sciences, Chinese Academy of Sciences, Beijing, 100085, China \\ b Laboratory of Water Pollution Control Technology, Research Center for Eco-Environmental Sciences, Chinese Academy of Sciences, Beijing, 100085, China \\ ${ }^{c}$ University of Chinese Academy of Sciences, Beijing, 100049, China \\ d Beijing Key Laboratory of Industrial Wastewater Treatment and Resource Recovery, Research Center for Eco-Environmental Sciences, Chinese Academy of Sciences, Beijing, 100085, China \\ e The National Engineering Laboratory for High Concentration and Refractory Organic Wastewater Treatment Technology, Chinese Academy of Sciences, Beijing, 100085, China
}

\section{H I G H L I G H T S}

- Effect of PVDF-CTFE content on phase inversion process was investigated.

- Hydrophobic membrane with excellent MD desalination performance was prepared.

- Effective pore passages were proposed for membrane permeability evaluation.

- Dehalogenation and membrane shrinkage obstruction were the mechanism for $\mathrm{NaOH}$ and ethanol solution.

\section{GRAPHICALA B STRACT}

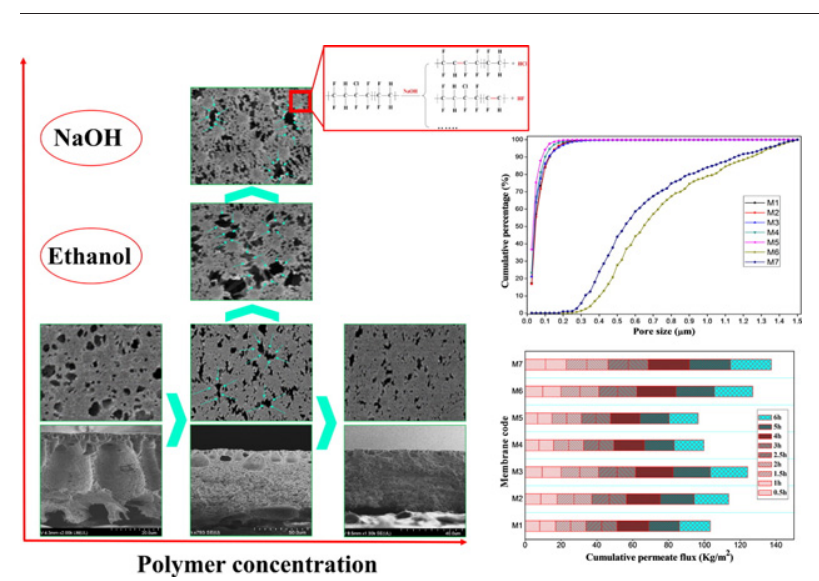

\begin{abstract}
A B S T R A C T
Desalination by membrane distillation (MD) have found rapid growth and diversified applications in recent decade, associated with it was the demand for hydrophobic membranes. Poly (vinylidene fluoride-cochlorotrifluoroethylene) (PVDF-CTFE) was used for hydrophobic membrane preparation with LiCl additive by non-solvent induced phase inversion (NIPS), the effect of polymer concentration was investigated in terms of membrane morphology, pore structure, hydrophobicity, thermal property, and membrane distillation (MD) performance to evaluation its potential in MD desalination. It was found that the solid-liquid demixing process showed more influence with increasing polymer content due to the delayed phase inversion process, which was responsible for the suppressed macrovoids, reduced pore size, higher hydrophobicity and pore interconnectivity. The melting temperature and crystallinity also increased due to the crystallization during membrane formation. M3 with $12 \%$ polymer content presents the best MD performance (permeate flux of $20.65 \mathrm{~kg} / \mathrm{m}^{2} \cdot \mathrm{h}$ with a salt rejection higher than 99.95\%). Ethanol and sodium hydroxide ( $\mathrm{NaOH})$ solution were applied as the second immersion bath to post-treat the nascent membranes. Pore enlargement effect was found for both post-treated membranes. However, the dehalogenation process was the most important mechanism for $\mathrm{NaOH}$, while the obstruction of partial shrinkage was the mechanism of ethanol solution. In a word, PVDF-CTFE hydrophobic
\end{abstract}

\footnotetext{
* Correspondence to: J. Wang, 18 Shuangqing Road, Haidian District, Beijing 100085, PR China. Tel.: + 861062849198 ; fax: + 861062849198 .

** Correspondence to: Y. Wei, 18 Shuangqing Road, Haidian District, Beijing 100085, PR China. Tel.: +86 102849109 ; fax: +86 1062849109.

E-mail addresses: junwang@rcees.ac.cn (J. Wang), yswei@rcees.ac.cn (Y. Wei).
} 
membrane show potential in MD desalination, especially when a second solution bath is used for membrane modification as the flux enhancement without the sacrifice of salt rejection.

(c) 2016 Elsevier B.V. All rights reserved.

\section{Introduction}

Hydrophobic membrane-based process like MD [1,2], membrane emulsification (ME) [3], osmotic distillation (OD) [4], pervaporation [5], and membrane crystallization ( $\mathrm{MCr}$ ) [6] have found various applications and shown proven advantages in desalination, wastewater treatment, gas separation, concentration and recovery of temperature sensitive materials $[7,8]$. The membrane applied in these process should presents hydrophobic nature firstly, along with the ideal pore structure with narrow pore distribution, low thermal conductivity, excellent chemical tolerance and mechanical strength $[9,10]$. The commercial ultrafiltration or microfiltration membranes which have been commonly applied can hardly meet all the criterions. Thus the commercial-scale hydrophobic membrane-based processes like MD remain challenging due to the constraint of commercially available high performance membranes and modules.

In recent decades, hydrophobic membrane preparation and membrane formation mechanism study have been a hotspot in membrane science. Most of these membranes are fabricated from polymeric materials due to the lower surface energy, lower cost and better processability, even hydrophobic-modified ceramic membranes also show potentials in hydrophobic membrane-based process [11-13]. Non-solvent induced phase inversion (NIPS), including immersion phase inversion, vapor-induced phase inversion (VIPS), and dry-wet phase inversion, is a versatile membrane preparation technology due to the mild operation conditions, easily controlling of membrane structure and performance [9,14]. Thus, poly(vinylidene fluoride) (PVDF) and PVDF-based copolymer got more attractions as compared to polytetrafluoroethylene (PTFE) and polypropylene (PP) [10,15,16], as they can dissolve in many common organic solvents.

NIPS process involves a heterogeneous casting solution including polymer, solvent, non-solvent, and/or additives, the phase inversion happened along with the exchange of solvent and non-solvent and the solidification of polymer-rich phase under specific ambient and operation conditions [14]. For semi-crystalline polymer like PVDF and its copolymers, the phase inversion was more complicated as both solidliquid demixing (crystallization, vitrification, or gelation) and liquid-liquid demixing happened [17-19]. Membrane structure and performance was easily affected as the phase inversion process was vulnerable to various factors. Among them, polymer concentration and additive present tremendous influences due to their remarkable thermodynamic and kinetic effects. The effect of polymer concentration has been widely studied for PVDF, PVDF-HFP, PVDF-TFE hydrophobic membranes [19-22]. However, although PVDF-CTFE has been applied for membrane preparation in the recent decade by NIPS for water treatment or electrolyte separator [23-25], the effect of polymer concentration was hardly reported, especially for hydrophobic membrane preparation. $\mathrm{LiCl}$ is one of the most commonly used additives which had found widely applications during hydrophobic membrane preparation. The use of $\mathrm{LiCl}$ is characterized by the strong interaction between $\mathrm{Li}^{+}$and solvent or polymer material. So the viscosity of casting solution increased significantly when LiCl was added, which may impede the exchange of solvent and non-solvent. The macrovoids was restricted and the crystalline structure showed in membrane surface and cross-section due to the lower phase inversion rate, i.e., the $\mathrm{LiCl}$ additive benefit the solid-liquid demixing process [19,25-27].

However, problems still exist for hydrophobic membrane in terms of additive residual, shrinkage, poor surface morphology and pore structure, which lead to poor performance and short membrane lifespan.
Even when a supporting material was applied to preventing membrane shrinkage, partial shrinkage still happened which tends to influence the pore structure [28]. The lower permeate flux, severe membrane wetting and fouling issue, and short lifespan impede the development of hydrophobic membrane application, especially for commercial expansion. Thus, membrane modification was a necessary prerequisite. Modification methods for hydrophobic membrane have been widely reported by state-of-art literatures, which mostly realized by doping, coating and grafting $[29,30]$. However, most of the modification method are complex and expensive. Post treatment by immersion with specific solution is a simple method which have been proved to improve membrane properties and performance [31-33]. The immersion of nascent membrane with a second solution especially liquid with low surface energy was proven to improve membrane structure and performance by preventing membrane shrinkage and further leaching out of additives or solvent. However, the effects of solution immersion on membrane morphology, pore structure, physico-chemical properties, and performance have been hardly reported. Meanwhile, as the PVDF hydrophobic membrane was commonly used under alkali or volatile organic solvent condition or cleaned by alkali, the stability is another most concerned issue. The effect of alkali immersion on membrane has also been studied to investigate the impact on membrane pore structure and their stability by simulating the condition of the membrane process under harsh condition [34-36]. Samsure et al. [37] also reported that the alkaline solution in mild condition had pore enlargement effect, which benefited the higher flux and improve the membrane properties.

In the present contribution, we prepared hydrophobic PVDF-CTFE flat-sheet membrane by NIPS (more precisely, dry-wet phase inversion) with the PVDF-CTFE/LiCl/DMAc/ $\mathrm{H}_{2} \mathrm{O}$ quaternary solution system. Effect of PVDF-CTFE concentration on membrane morphology, pore structure, thermal and crystalline properties, and hydrophobicity were carefully investigated. Ethanol and $\mathrm{NaOH}$ solutions were used as the second immersion bath to investigate their effects on membrane structure and properties, as well as the stability of membranes after post-treatment. The hydrophobic membrane performance was also assessed by a $6 \mathrm{~h}$ continuous DCMD operation to evaluate its potential in MD desalination.

\section{Experimental}

\subsection{Materials}

PVDF-CTFE copolymer (Solvay Solef ${ }^{\circledR} 32008, \mathrm{Mw}=280,000$ ) was obtained from Solvay Solexis for membrane preparation due to its hydrophobic nature. Dimethylacetamide (DMAc, >99.0\%), purchased from Shanghai Jingwei Chemical Co., Ltd., was used as solvent. LiCl (AR, >97.0\%), supplied by Tianjin Guangfu Research Institute of Fine Chemical Engineering, was applied as additive. 50\% Ethanol (GR, > $99.7 \%$ ) and $5 \mathrm{~g} / \mathrm{L} \mathrm{NaOH} \mathrm{(AR,} \mathrm{>96 \% )} \mathrm{solutions} \mathrm{were} \mathrm{used} \mathrm{as} \mathrm{the} \mathrm{second}$ immersion bath to modify the membrane. $35 \% \mathrm{NaCl}$ solution was used as the feed solution, deionized (DI) water was firstly used in the permeate side in DCMD test. Tap water was used as non-solvent in the coagulation bath.

\subsection{Membrane preparation and post treatment}

The PVDF-CTFE flat-sheet membranes were prepared by NIPS, which combined the solvent evaporation process and immersion phase inversion process induced by coagulation bath. At first, the copolymer was 
dried at $50{ }^{\circ} \mathrm{C}$ in an oven for $24 \mathrm{~h}$ prior to the solution preparation for desiccation. Then five polymer solutions were prepared by mixing pre-dried PVDF-CTFE copolymer powder, solvent DMAc and additive $\mathrm{LiCl}$ in a sealed flask and stirred at $30{ }^{\circ} \mathrm{C}$ for $24 \mathrm{~h}$ (detailed composition can be found in Table 1). The homogeneous polymer solutions were then allowed for bubble removal in an oven at $30^{\circ} \mathrm{C}$ for $24 \mathrm{~h}$.

To prevent shrinkage of the PVDF-CTFE function layer due to its low surface energy, a support material should be applied. According to the previous work [38], the hydrophilic PET nonwoven fabric was used in this work. A piece of fabric $(18 \mathrm{~cm} \times 20 \mathrm{~cm})$ was well-pressed attached to the clean glass plate to avoid corrugation. The casting solution was subsequently spread uniformly on the surface of the supporting layer by a casting knife with a gap of $0.25 \mathrm{~mm}$ in an oven at $50{ }^{\circ} \mathrm{C}$. The exposure duration for all membranes was $15 \mathrm{~s}$, after which the nascent membrane was immersed into the non-solvent coagulation bath at $25{ }^{\circ} \mathrm{C}$ for $24 \mathrm{~h}$. Then the prepared membrane was removed from the coagulation bath and washed with running DI water to remove the residual additive and solvent. Finally, the wet membranes were dried at room temperature and preserved for further measurement and observation.

For membrane post treatment and stability study, the wet membrane M3 was take out from coagulation bath and transferred to a second bath for $8 \mathrm{~h}$ at ambient temperature immediately (the detailed information can be also found in Table 1). At last, the membranes were washing again with running DI water and then dried at room temperature.

\subsection{Morphological study}

Membrane morphology visually offers topography and pore structure of membranes, and it also provides the information for predicting the phase inversion process and evaluating membrane performance. In this work, field emission scanning electron microscope (FE-SEM, HITACHI SU8020, Hitachi, Japan) was applied. The membrane surface and cross-section were observed under standard high-vacuum conditions at $3.00 \mathrm{kV}$. The samples were freeze-fractured by liquid nitrogen for cross-section observation, and samples for both surface and crosssection test were coating with gold nanoparticles under vacuum with a HITACHI E-1010 Ion device (Hitachi, Japan).

During SEM observation, surface topography would significantly reflect in SEM images by the brightness. Pore edges were highlighted by the secondary electrons, so the deeper the position the darker as it presents in SEM images and vice versa. Thus it was acceptable that the grayscale values of the individual pixels in SEM micrographs could indicate the state of membrane surface with acceptable accuracy although some discrepancies still exist [39,40]. A 10,000 $\times$ magnified SEM image with a range of $8.8 \mu \mathrm{m} \times 12.7 \mu \mathrm{m}$ for all membrane were applied for image analysis by Image $\mathbf{J}$ software (National Institutes of Health, USA). A three-dimension graph was plotted by the intensities of pixels in a grayscale, which can present the topography of membrane surface. Meanwhile, the standard deviation of grayscale values was also calculated to show the roughness of the membrane, which was defined as the SEM roughness index [41].

Table 1

Composition of casting solutions and second immersion bath.

\begin{tabular}{lclll}
\hline $\begin{array}{l}\text { Membrane/solution } \\
\text { code }\end{array}$ & $\begin{array}{l}\text { PVDF-CTFE } \\
\text { (wt.\%) }\end{array}$ & $\begin{array}{l}\text { LiCl } \\
\text { (wt.\%) }\end{array}$ & $\begin{array}{l}\text { DMAc } \\
\text { (wt.\%) }\end{array}$ & $\begin{array}{l}\text { Second immersion } \\
\text { bath }\end{array}$ \\
\hline $\begin{array}{l}\text { Effect of PVDF-CTFE concentration: } \\
\text { M1 }\end{array}$ & & & \\
M2 & 8 & 5 & 87 & - \\
M3 & 10 & 5 & 85 & - \\
M4 & 12 & 5 & 83 & - \\
M5 & 15 & 5 & 80 & - \\
Effect of post-treatment: & 18 & 5 & 77 & - \\
M6 & 12 & 5 & 83 & $50 \%$ ethanol solution \\
M7 & 12 & 5 & 83 & 5 g/L NaOH solution \\
\hline
\end{tabular}

\subsection{Pore structure characterization}

Membrane pore structure is an integrated concept including porosity (both surface and overall porosity), pore size and pore size distribution, pore interconnectivity, and pore shape. The salt rejection was influenced by surface pore structure and hydrophobicity. The flux was influenced by the effective pore passage for vapor, which was determined by both pore size, porosity, and pore interconnectivity. Pore interconnectivity can be view as the number of the vapor passage, which has same influence as pore size and porosity in determining membrane permeate flux [16] pore structure also determines membrane roughness, lifespan, and even membrane hydrophobicity.

The image-pro-plus 6.0 software (Media Cybernetics, USA) can offer an image analysis method based on the grayscale value of each pixel, whereby the pore in membrane surface can be distinguished and the information of size or shape can be calculated. So the surface pore structure in terms of porosity, pore size and its distribution were obtained by SEM image analysis by through the grayscale calculation. The same SEM image was used for pore structure analysis, all surface pores were marked for calculation of the pore area, average pore size, and pore distribution data [16,39-40]. The surface porosity was calculated by proportion of total area of surface pore to total measured surface area. The overall porosity, i.e., void volume fraction, was measured by the gravimetric method. The dry membrane was tear off from the nonwoven fabric, then immersed in ethanol solution and DI water in sequence for each $24 \mathrm{~h}$ to fulfill all pores with ethanol then displace it with water. The porosity $(\varepsilon)$, which was the volume ratio of pores and the membrane, was calculated by the following equation:

$\varepsilon=\frac{\left(M_{w}-M_{d}\right) / \rho_{w}}{M_{d} / \rho_{w}\left(M_{w}-M_{d}\right) / \rho_{w}}$

Where $M_{w}$ is the weight of the wet membrane, $M_{d}$ is the weight of the dry membrane after drying in oven, $\rho_{w}$ and $\rho_{p}$ are the density of water and membrane, respectively.

The membrane pore size in terms of the bubble point, minimum, and mean pore size and pore size distribution of the flat sheet membrane was also investigated by the capillary flow method (also known as the wet/dry flow method) using a Capillary Flow Porometer Porolux 1000 (Porometer, Belgium) to study their influences on the permeation properties. The membrane was wetting by liquid named Porefil (IB-FT $\mathrm{GmbH}$, Germany) with a surface tension and density of 16 dyn $/ \mathrm{cm}$ and $1.87 \mathrm{~g} / \mathrm{mL}$. The wetted membrane coupon was fixed in the Pololux 1000 and air stripping with nitrogen $\left(\mathrm{N}_{2}\right)$ to blowout the Porefil by increasing the pressure gradually, the first recorded pore was bubble point pore. After that, the pressure was still increased and a wet flow curve was obtained by recording the pressure and the gas flow under relevant condition. Then a same process was reduplicated for the dry membrane coupon by increasing the $\mathrm{N}_{2}$ pressure stepwise at a presented pressure to get the dry curve. According to wet flow curve and dry flow curve, the pore size and pore size distribution data were calculated by the attached software.

\subsection{Hydrophobicity}

Membrane hydrophobicity was characterized by the contact angle with water $\left(C A_{w}\right)$ in this study, the $C A_{w}$ was measured by the sessile liquid drop method using an OCA 15EC Video-Based Contact Angle Meter (Data Physics, Germany). At least five different positions of each membrane were measured and the average value was reported.

\subsection{Thermal and crystalline properties}

The surface infrared spectra were recorded by a Nicolet iS10 FTIR spectrometer (Thermo Scientific, USA) to investigate the effect of the membrane formation and the post treatment process on the chemical 
structure of PVDF-CTFE copolymer. The samples were placed on the sample holder and all spectra were recorded in a wave number range between $650 \mathrm{~cm}^{-1}$ and $3000 \mathrm{~cm}^{-1}$ by cumulating 64 scans at a resolution of $4 \mathrm{~cm}^{-1}$ in attenuated total reflection (ATR) mode. As $\alpha$ phase and $\beta$ phase are the two common PVDF polymorphs after NIPS, the proportion of $\alpha$ phase and $\beta$ phase content was used to investigate the crystalline structure variation. According to the spectrum, the $\beta$ phase content $F(\beta)$ is calculated by the following equation which has been widely applied [42-44].

$$
F(\beta)=\frac{A_{\beta}}{\left(K_{\beta} / K_{\alpha}\right) A_{\alpha}+A_{\beta}}
$$

Where $A_{\alpha}$ and $A_{\beta}$ represent the absorbencies at 766 ( $\alpha$ phase) and $840 \mathrm{~cm}^{-1}$ ( $\beta$ phase), respectively. $K_{\alpha}$ and $K_{\beta}$ are the absorption coefficient at the respective wave number, the value of which ware $6.1 \times$ $10^{4}$ and $7.7 \times 10^{4} \mathrm{~cm}^{2} / \mathrm{mol}$, respectively.

The thermal behaviour and crystallinity of the membrane was determined by differential scanning calorimeter (DSC) using a DSC 2 STAR $^{\mathrm{e}}$ system (Mettler Toledo, Switzerland). About $5 \mathrm{mg}$ membrane coupon was torn off from the nonwoven fabric and placed in a $40 \mu \mathrm{L}$ aluminum crucibles and heated from 50 to $250{ }^{\circ} \mathrm{C}$ at a rate of $10{ }^{\circ} \mathrm{C} / \mathrm{min}$. The heat flow was recorded and then the crystallinity $(\chi)$ was calculated by the following equation.

$\chi=\frac{\Delta H_{m}}{\Delta H_{100 \%}}$

As PVDF polymorphs also possess significant impact on the crystallinity, the crystallinity considering of polymorphs $\left(\chi_{p}\right)$ of the membranes after post-treatment was also calculated by the following equation.

$\chi_{p}=\frac{\Delta H_{m}}{x\left(\Delta H_{100 \%)} \alpha+y\left(\Delta H_{100 \%}\right)_{\beta}\right.}$

Where $x, y$ are the weight fraction of $\alpha$ phase and $\beta$ phase; $\Delta H_{m}$ is the recorded melting enthalpy of the membrane; $\Delta H_{100 \%},\left(\Delta H_{100 \%}\right)_{\alpha}$ and $\left(\Delta H_{100 \%}\right)_{\beta}$ represent the melting enthalpy of the pure crystalline PVDF, PVDF $\alpha$ phase and $\beta$ phase which is reported to be 104.9, 93.04, and $103.4 \mathrm{~J} / \mathrm{g}$, respectively [44].

\subsection{DCMD experiments}

DCMD desalination experiments were performed in a lab-scale setup to evaluate membrane performance, and the set-up of the DCMD could be found in Fig. 1. The membrane (effective area was $5.218 \times 10^{-3} \mathrm{~m}^{2}$ ) was tightly clamped in the flat-sheet membrane module. The feed solution ( $35 \mathrm{~g} / \mathrm{L} \mathrm{NaCl}$ solution) circulate in contact with the PVDF-CTFE top layer in the left side and distillated water (about $30 \mu \mathrm{S} / \mathrm{cm}$ ) was circulate in contact with PET supporting layer on the right side acting as the condensate water (Fig. 1). The flow rate of the feed and permeate were kept constant at $65 \mathrm{~L} / \mathrm{h}$ and $50 \mathrm{~L} / \mathrm{h}$. The temperature of the feed and permeate inlet were kept at $25{ }^{\circ} \mathrm{C}$ and $55^{\circ} \mathrm{C}$. A 6 h continuous MD test was running, the permeate weight and conductivity was record at set intervals. The permeate flux was the weight per unit area in unit time (i.e., $\mathrm{kg} /\left(\mathrm{m}^{2} \cdot \mathrm{h}\right)$ ). The salt rejection was calculated as follows:

$R=\frac{C_{\text {feed }}-C_{\text {permeate }}}{C_{\text {feed }}}$

Where $C_{\text {feed }}$ and $C_{\text {permeate }}$ are the salt concentrations of the feed and permeate, respectively.

\section{Results and discussion}

\subsection{Effect of polymer concentration on membrane structure and properties}

Fig. 2 illustrates the surface and cross-section morphology of PVDFCTFE flat-sheet membranes prepared with different PVDF-CTFE contents. For membrane surface, three significant variations were clearly presented: 1) The surface pore turned from regular round to irregular but interconnected shape as the polymer concentration increased from $8 \%$ to $18 \% ; 2$ ) The surface porosity decreased dramatically when the concentration was higher than $15 \%$; 3 ) The roughness represented by SEM roughness index increased firstly and then decreased along with the increasing concentration as can be found in Fig. 2C, while M3 showed the highest roughness (SEM roughness index $=45.32$ ). The morphology and pore structure in cross-section also showed significant variation as increasing the concentration. The macrovoids were suppressed when increasing the concentration especially when polymer content was higher than $12 \%$, the membranes turned from the asymmetric structure with macrovoids across the entire section as M1 shown to approximately symmetric structure without macrovoids as M5 shown. However, the interconnectivity increased in both macrovoids walls and the sponge-

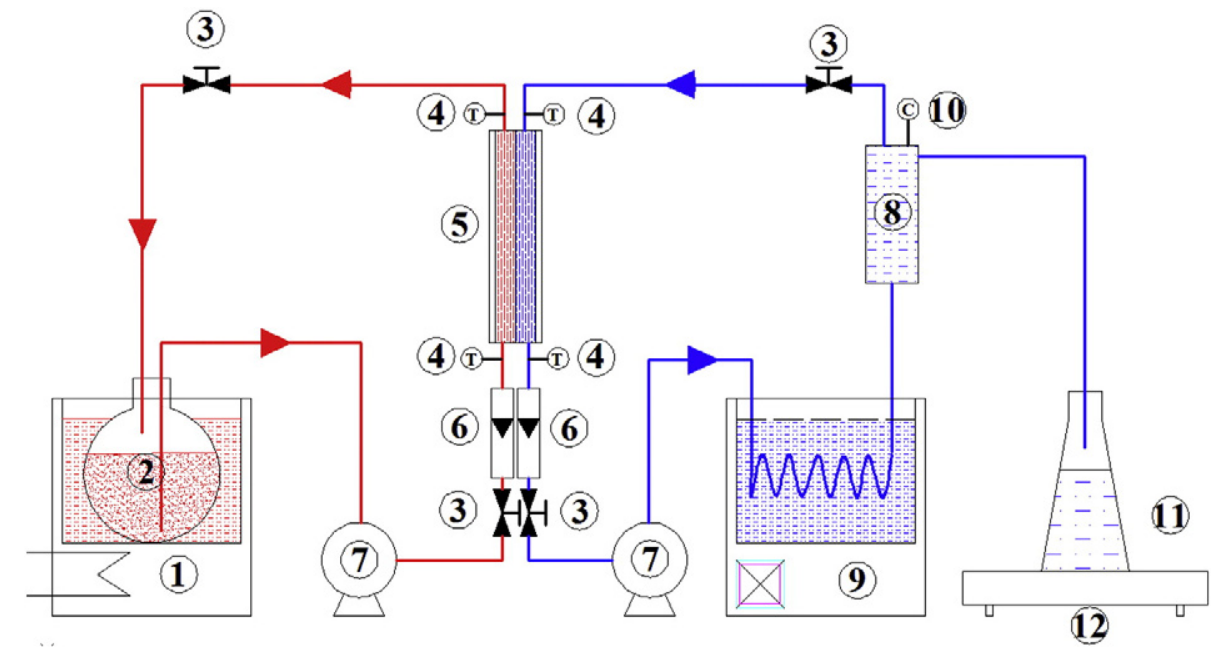

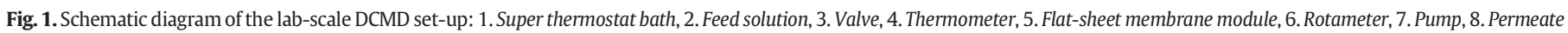
collector, 9. Cryostat, 10. Conductivity meter, 11. Conical flask 12. Balance. 

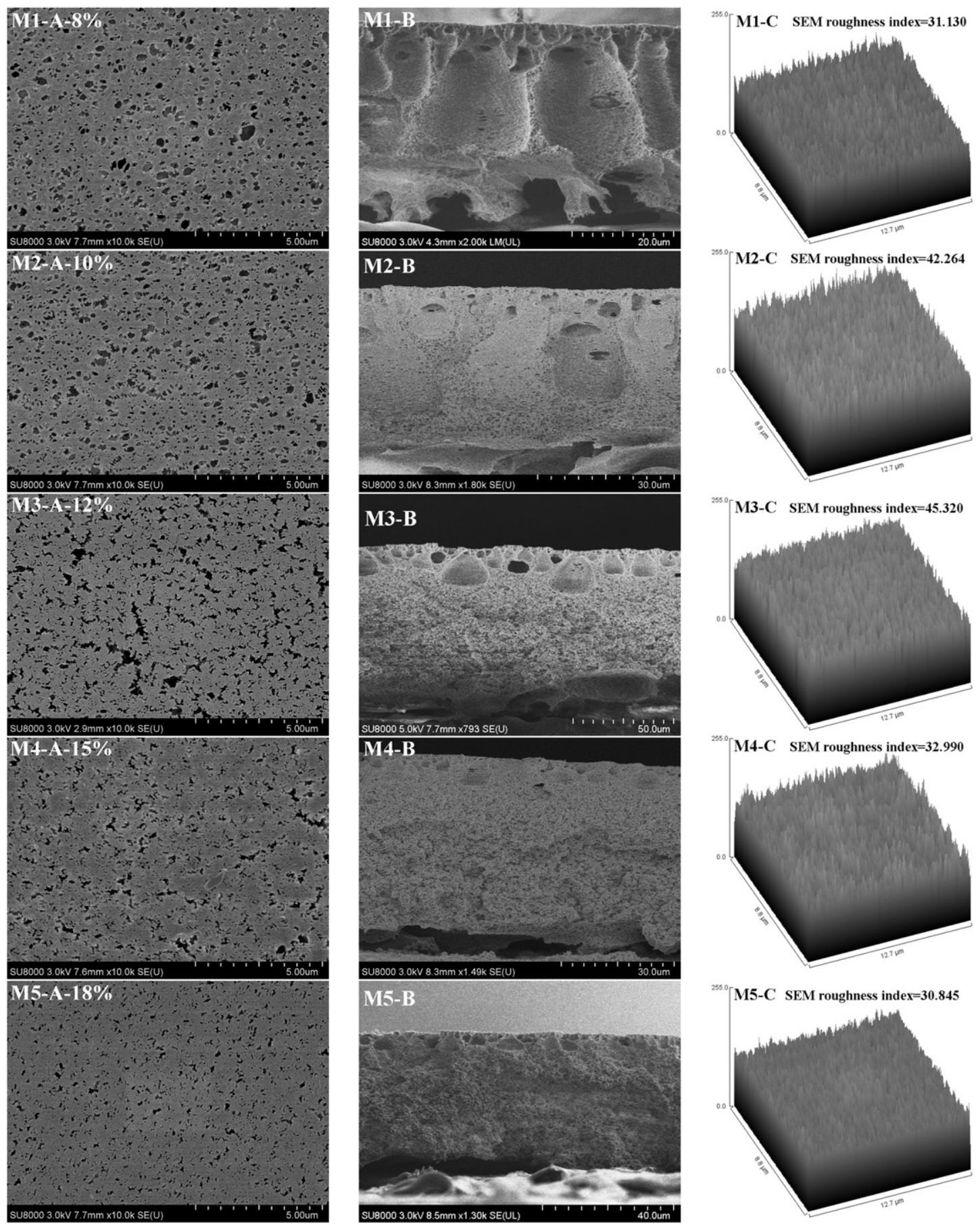

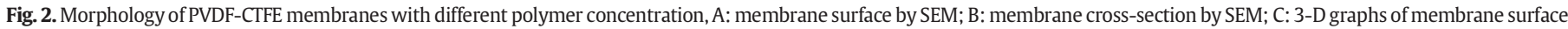
by image $\mathrm{J}$.

like layer and the crystals appeared when polymer concentration was higher than $12 \%$. The morphology and pore structure variation according to polymer concentration in casting solution also reported by previous literatures where PVDF and PVDF-HFP were used for membrane preparation, and the phase inversion process during membrane formation was believed to be the reason $[16,20,27,42]$. When the polymer concentration was increased, the viscosity of casting solution would be higher in consequence, especially when $\mathrm{LiCl}$ was added as additive in the solution $[25,27]$. The exchange of solvent and non-solvent which induced the liquid-liquid demixing process was impeded because of the higher polymer concentration. Meanwhile, the polymer-rich phase occupied more position during phase inversion process. As a result, the porosity decreased due to the decrease of polymer-lean phase, which was believed to form pores after phase inversion. And the macrovoids would be suppressed because of the slower phase inversion rate. On the contrary, the solid-liquid demixing showed more impact on phase inversion process as the concentration was higher. The solid-liquid demixing process benefit the polymer crystallization process, and the crystals was responsible for the interconnected pore structure both in surface and cross-section as shown in Fig. 2B due to the formation of crystals aggregate pores and the increasing roughness when concentration was lower than $12 \%$. However, the crystals tend to aggregate together when polymer concentration was higher ( $15 \%$ in this work as shown in Fig. 2 ), so the roughness would decrease significantly. The lower porosity for 
Table 2

Porosity and pore size of the PVDF-CTFE membranes.

\begin{tabular}{|c|c|c|c|c|c|}
\hline Membrane code & Porosity $^{\mathrm{a}}(\%)^{\mathrm{b}}$ & Mean pore size ${ }^{\mathrm{a}}(\mathrm{nm})$ & Porosity $^{\mathrm{c}}(\%)^{\mathrm{d}}$ & Mean pore $\operatorname{size}^{\mathrm{c}}(\mu \mathrm{m})$ & Bubble point pore size ${ }^{\mathrm{c}}(\mu \mathrm{m})$ \\
\hline \multicolumn{6}{|c|}{ Effect of PVDF-CTFE concentration } \\
\hline M1 (8\%) & 18.43 & 61.44 & $78.14 \pm 0.84$ & 0.269 & 0.803 \\
\hline M2 (10\%) & 20.51 & 62.01 & $71.27 \pm 1.55$ & 0.189 & 0.499 \\
\hline M3 (12\%) & 20.87 & 58.85 & $70.24 \pm 1.82$ & 0.173 & 0.410 \\
\hline M4 (15\%) & 14.31 & 51.19 & $64.01 \pm 1.96$ & 0.165 & 0.415 \\
\hline M5 (18\%) & 11.21 & 41.86 & $62.17 \pm 2.73$ & 0.112 & 0.209 \\
\hline \multicolumn{6}{|c|}{ Effect of post-treatment } \\
\hline M6 (ethanol) & 21.16 & 95.14 & $71.27 \pm 0.90$ & 0.139 & 0.292 \\
\hline $\mathrm{M} 7(\mathrm{NaOH})$ & 18.04 & 73.37 & $72.42 \pm 1.06$ & 0.122 & 0.268 \\
\hline
\end{tabular}

a Represents the surface pore structure.

b Surface porosity was the area ratio of pores and the membrane surface in SEM image.

c Represents the overall pore structure.

d Overall porosity was the volume ration of overall pores and the membrane.

membrane M4 and M5 was another reason for the lower roughness as the roughness was a reflection of membrane surface pore structure and topography $[9,45,46]$. It also worth mention that the porosity of membrane surface showed no significant variation for M1 to M3 even the concentration increased from $8 \%$ to $12 \%$, which was attributed to the irregular interconnected pores.

Table 2 presents the surface and overall pore structure of the PVDFCTFE flat-sheet membranes. The overall porosity and mean pore size decreased along with the polymer concentration, resulting from the less polymer-lean phase and the suppression of the macrovoids during membrane formation as shown in Fig. 2B. While the surface porosity increased from $18.43 \%$ to $20.87 \%$ as the concentration increased to $12 \%$, after that the porosity would decrease when further increasing the polymer content. The surface mean pore size possessed a same trend when increase polymer content in casting solution. The formation of the interconnected irregular pores due to the polymer solid-liquid demixing was sure to be the reason, as can be verified by the SEM micrographs (Fig. 2A).

The distributions of both surface and overall pores were shown in Fig. 3. Generally speaking, all membranes presented narrow distribution for both surface and overall pores. The inserted figures (percentage of pores with similar pore size) in Fig. 3A showed that the surface pore size for all membranes concentrated on $20 \mathrm{~nm}$ to $40 \mathrm{~nm}$. However, the distribution had a trend of M1 > M2 > M3 > M4 > M5 as the
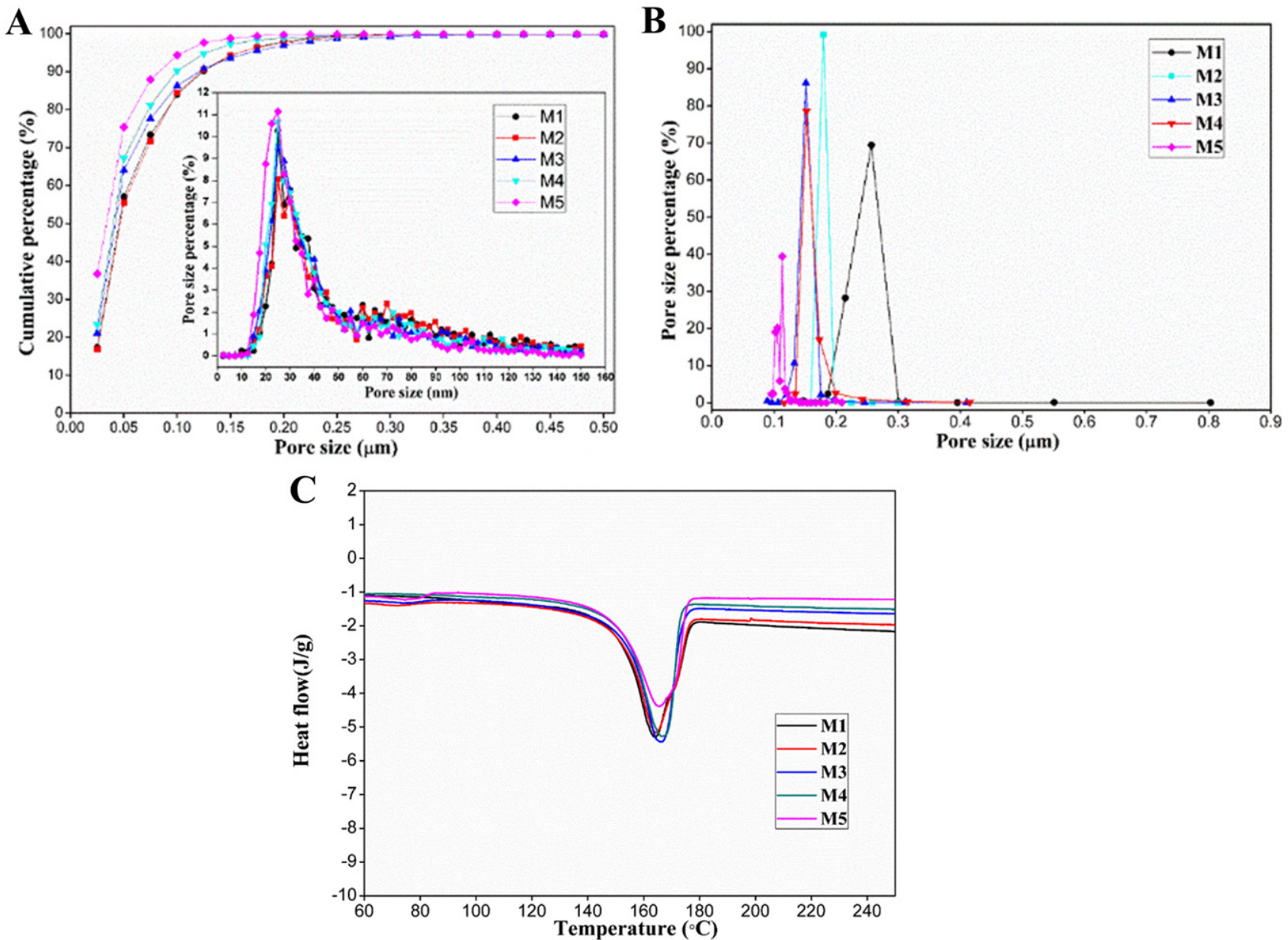

Fig. 3. Pore size distribution and DSC curve of PVDF-CTFE membranes with different polymer concentration, A: surface pore structure; B: overall pore structure; C: DSC curves. 
cumulative percentage curve (Fig. 3A) showed. That means the percentage of bigger pores decreased as the polymer concentration increased. The overall pore structure showed the same trend as can be found in Fig. 3B, the pore distribution became narrower and the pore size decreased as more PVDF-CTFE was added. Two reasons can be attributed to the pore structure variation: 1 ) The polymer-rich phase occupied more space and solidified when phase inversion was finished with increasing the content of polymer; 2) The higher viscosity impeded the development of macrovoids. It also worth mention that the distribution variation of surface pores was less apparent as compared to overall pores as shown in Fig. 3. Although the surface porosity and number of pores decreased when increasing PVDF-CTFE content as shown in Fig. 2 , the pore size and pore distribution showed a slighter difference. The formation of the interconnected irregular shape pores was believed to be the reason which can offset the pore-wane effect of increasing polymer concentration.

The membrane hydrophobicity in terms of $\mathrm{CA}_{\mathrm{w}}$ was presented in Table 3. It can be found that the $\mathrm{CA}_{\mathrm{w}}$ also firstly increased and then decreased when the concentration was higher than $12 \%$, which presented a same trend with roughness as shown in Table 2 . The crystallization and interconnected surface pore structure was the reason for the increase of roughness and $\mathrm{CA}_{\mathrm{w}}$ when polymer concentration was lower than $12 \%$; however, the roughness decreased due to the aggregation of crystals and less porous surface as more PVDF-CTFE was added. The correlativity of membrane hydrophobicity/hydrophilicity and roughness has been widely reported $[46,47]$. When water droplet was drip to membrane surface, it contacted with solid substrate and the trapped air because of the polymer bulge and pores in membrane surface. So for a hydrophobic membrane, the tested $C \mathrm{~A}_{\mathrm{w}}$ was higher than the practical $\mathrm{CA}_{\mathrm{w}}$ of the membrane material according to the Cassie-Baxter state [48].

The DSC curves of the membranes were shown in Fig. 3C, the melting temperature and crystallinity data were presented in Table 3. It can be found that the melting temperature and crystallinity increased significantly along with the polymer concentration when the concentration was higher than $12 \%$. The crystallization process during membrane formation as discussed in Fig. 2 was believed to be the reason. The liquid-liquid demixing dominated the phase inversion process due to the rapid exchange rate of solvent and non-solvent when the polymer content was low. The solid-liquid process possessed more impact along with the increasing polymer concentration, thus the polymer crystallization process found more place to proceed.

\subsection{Effect of polymer concentration on membrane performance}

The PVDF-CTFE hydrophobic flat-sheet membranes were applied to DCMD desalination process, the results of permeate flux and salt rejection during the continuous $6 \mathrm{~h}$ operation were presented in Fig. 4 . The flux in the first half hour was lower for all membranes because the temperatures of both feed and permeate side have not reaching an equilibrium state, and it kept stable during subsequent sample duration. The permeate flux increased firstly along with polymer concentration

Table 3

Hydrophobicity, melting temperature and crystalline property of PVDF-CTFE membranes.

\begin{tabular}{lrllll}
\hline Membrane code & $\mathrm{CA}_{\mathrm{w}}\left({ }^{\circ}\right)$ & $\mathrm{T}_{\mathrm{f}}\left({ }^{\circ} \mathrm{C}\right)$ & $\chi(\%)$ & $F(\beta)(\%)$ & $\chi_{\mathrm{p}}(\%)$ \\
\hline \multicolumn{2}{l}{ Effect of PVDF-CTFE concentration } & & & & \\
M1 (8\%) & $95.52 \pm 4.01$ & 163.81 & 54.23 & - & - \\
M2 (10\%) & $96.84 \pm 2.37$ & 164.31 & 53.87 & - & - \\
M3 (12\%) & $97.28 \pm 2.36$ & 166.14 & 58.07 & 42.55 & 62.51 \\
M4 (15\%) & $92.27 \pm 1.25$ & 166.55 & 58.11 & - & - \\
M5 (18\%) & $90.19 \pm 2.25$ & 165.34 & 59.57 & & \\
\multicolumn{2}{l}{ Effect of post-treatment } & & & & \\
M6 (Ethanol) & $92.37 \pm 1.58$ & 165.46 & 58.65 & 42.25 & 63.14 \\
M7 (NaOH) & $82.74 \pm 6.53$ & 163.57 & 55.97 & 42.75 & 60.23 \\
\hline
\end{tabular}

Note: $\mathrm{T}_{\mathrm{f}}$ represents the melting temperature, $\chi$ represents crystallinity, $\mathrm{F}(\beta)$ was the content of $\beta$ phase, $\chi_{\mathrm{p}}$ was the crystallinity in consideration of polymer polymorphs.
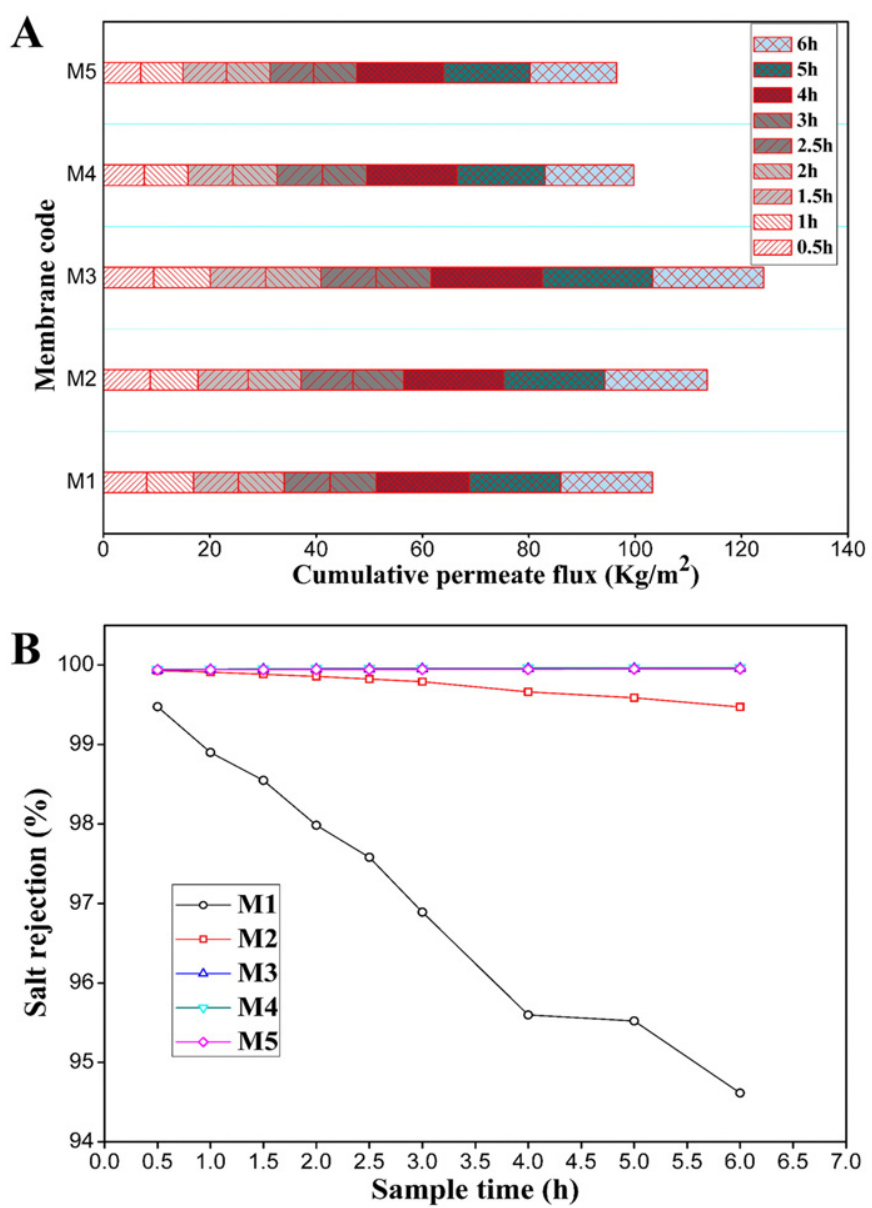

Fig. 4. Permeability of PVDF-CTFE membranes with different polymer concentration, A: permeate flux; B: salt rejection.

when the concentration was lower than $12 \%$, and then it decreased when further increase the concentration (Fig. 4A). The salt rejection decreased drastically for M1 as shown in Fig. 4B, and also decreased unceasing for M2 during the continuous operation. While for M3 to M5, the salt rejection kept higher than $99.95 \%$ and the conductivity decreased during the operation.

In the DCMD, the membrane surface layer functioned as the separator of the liquid and vapor which allows the vapor pass through the membrane pore passage. That is, the salt rejection was influenced by surface pore structure (i.e. pore size, pore distribution, and pore interconnectivity) and hydrophobicity. However, the flux was influenced both by surface structure and the effective pore passage for vapor in membrane cross-section. The membrane with bigger surface pore size like M1 and M2 has lower salt rejection and anti-wetting property as bigger pores means lower liquid entry pressure (LEP) [49]. The decrease in salt rejection shows a sign of pore wetting. The pore passage was affected by both pore size and pore interconnectivity, which can be viewed as the size and quantity of the passage. When increasing the polymer concentration, the pore size and porosity decreased but pore interconnectivity increased as discussed in Section 3.1. When the concentration was lower than $12 \%$, the increasing interconnectivity possess more influence, i.e., the number of passages increased quickly even their size decreased, so the flux increased. When further increase the concentration, the flux presents a decreasing trend as the pore size and porosity decreased significantly as can be found in Table 2 . The effective pore passage is also worth extending to other membrane process (pressuredriven, thermal-driven, or electric-driven) as the study of pore size and porosity was not enough to state the membrane process. It was also worth noting from the DCMD test that M1 and M2 were not suitable 
for MD desalination process due to the low rejection and anti-wetting property. M3, which showed excellent morphology, pore structure, and hydrophobicity presented the optimal MD performance with the highest flux and stable salt rejection (permeate flux of $20.65 \mathrm{~kg} / \mathrm{m}^{2} \cdot \mathrm{h}$ with a salt rejection higher than 99.95\%.). Meanwhile, the permeate flux and salt rejection kept stable during the $6 \mathrm{~h}$ continuous DCMD test.

\subsection{The effect of post treatment on membrane structure}

The surface morphology and pore structure of the PVDF-CTFE membrane after post treatment by ethanol and $\mathrm{NaOH}$ were presented in Fig. 5. The surface interconnectivity increased for all membranes as compared to the virgin membrane M3 shown in Fig. 2. The SEM roughness index decreased from 45.320 of the virgin membrane to 40.776 (M6) and 34.209 (M7), indicating that $\mathrm{NaOH}$ presents stronger influence on membrane surface pore structure and surface state. However, no significant variations showed in membrane cross-section after post-treatment by both solutions, even when magnified images of the top layer were analyzed as the inserted images shown in Fig. 5B. It means the post-treating process has subtle influence to the overall structure, but presents strong impact on membrane surface pore structure. As the surface layer is the function layer during membrane process which has intense relation to rejection and permeate flux, the post-treating process should not be ignored for membrane preparation.

The variations of surface and overall porosity after post-treatment were presented in Table 2. The surface pore size increased for both post-treated coupons, which of M6 was $95.14 \mathrm{~nm}$ as compared to $58.85 \mathrm{~nm}$ of the virgin membrane. However, the surface porosity showed a subtle increase to $21.16 \%$ for M6, and it decreased a little to $18.04 \%$ after $\mathrm{NaOH}$ immersion as compared to the virgin membrane (20.87\%). The overall porosity and pore size showed a minor variation with a slight increase for both post-treated membranes, further confirmed that the overall structure was slightly influenced after immersion with a second solution bath. The surface and overall pore distribution was offered in Fig. 6, which present same information about the pore size. It can be found that the distribution became
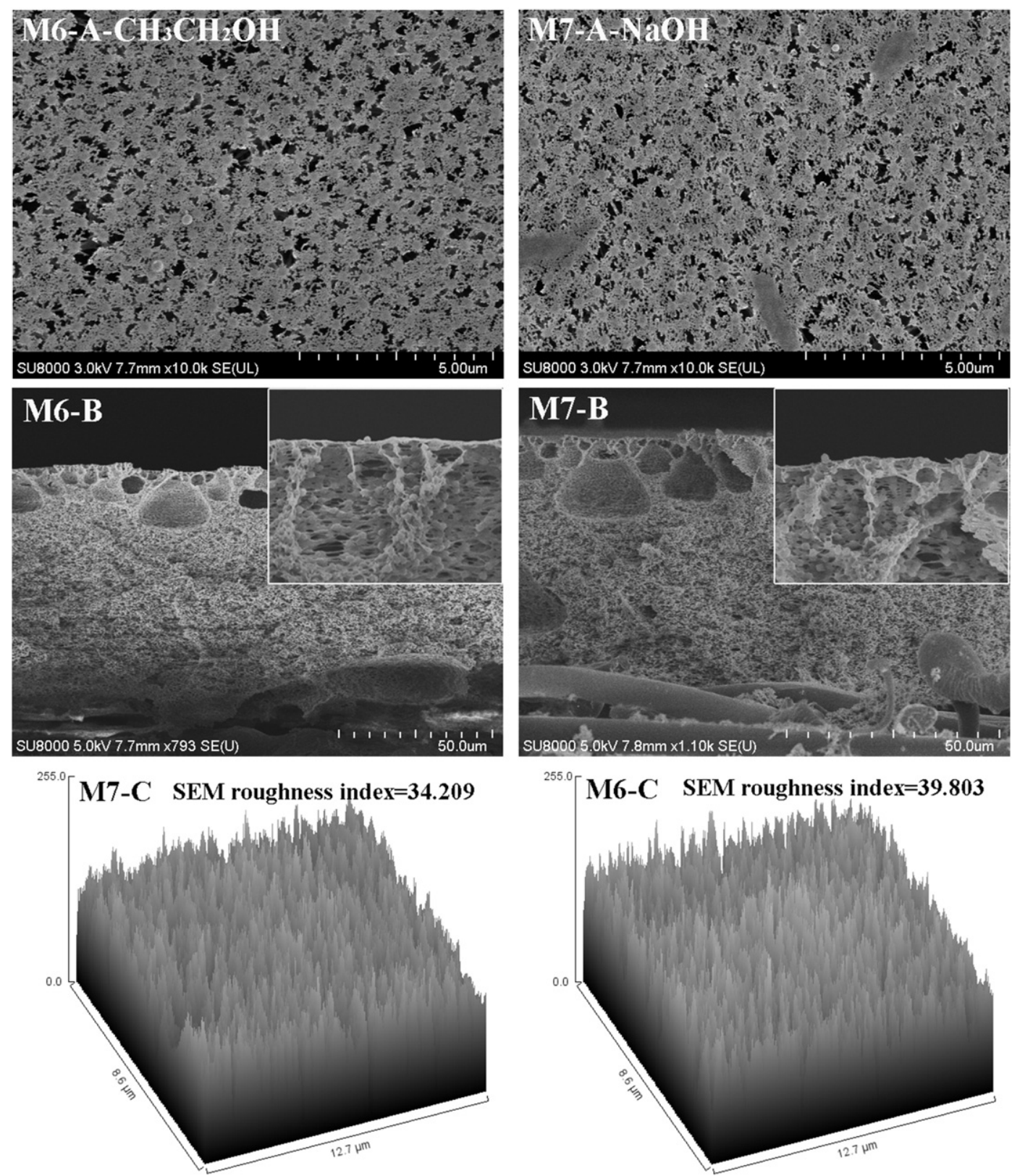

Fig. 5. Morphology of PVDF-CTFE membranes after post-treatment, A: membrane surface by SEM; B: membrane cross-section by SEM; C: 3-D graphs of membrane surface by image J. 
A

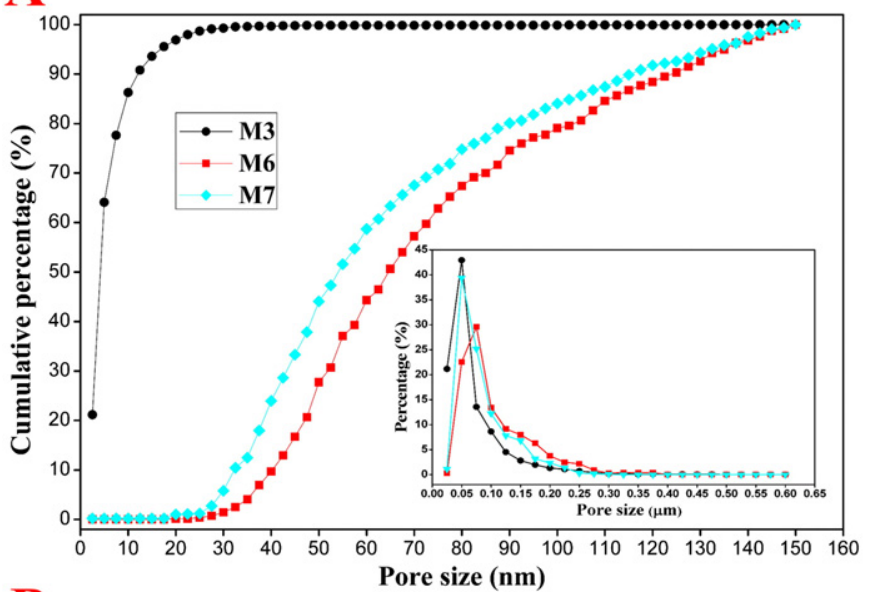

B

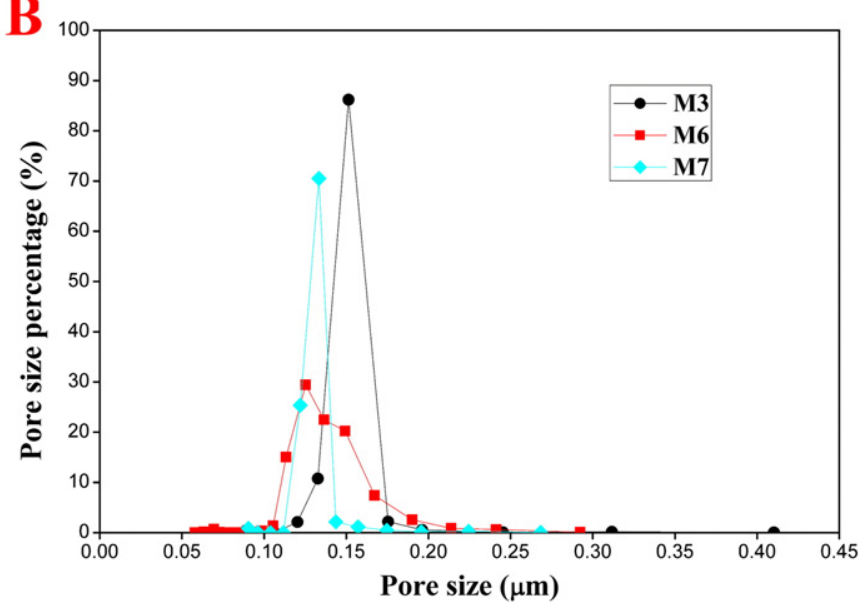

Fig. 6. Pore size distribution of virgin PVDF-CTFE membrane and the membranes after post-treatment, A: surface pore structure; $B$ : overall pore structure.

significantly broaden after post-treatment for both surface and overall pore, while M6 has the most broaden distribution.

As generally known, membrane shrinkage happened frequently especially for polymer with low surface energy. Supporting material was commonly used to prevent the shrinkage and eliminate its pore-wane effect. However, the partial shrinkage would still happened even the PET supporting material was applied [28]. When a second solution bath especially solution with low surface energy was used to treat membranes, the effect of partial shrinkage on pore structure can be offset. So the pore size and distribution would increase as a consequence, especially for M6 as ethanol was applied. Meanwhile, the dissolve out of the residual additive and other impurities was believed to be another reason for the variation of membrane structure especially for membrane surface.

\subsection{The effect of post-treatment on membrane thermal and crystalline} properties

FTIR analysis has been performed to investigate the effect of posttreatment on the PVDF-CTFE membranes in terms of structural changes in chemical groups and crystal structure. As can be seen from Fig. 7A, characteristic bands appeared at 763, 862, 976, 1073, 1173, 1206, and $1423 \mathrm{~cm}^{-1}$ were caused by PVDF a-phase, while other peaks were observed at 840 and $1276 \mathrm{~cm}^{-1}$ could be attributed to $\beta$-phase $[24,44]$. It was significant that a new peak at $1650 \mathrm{~cm}^{-1}$ appeared in $\mathrm{M} 7$, which was attributed by the carbon-carbon double bond $(-\mathrm{CF}=\mathrm{CH}-$ ). It indicated that the dehydrofluorination and dehydrochlorination
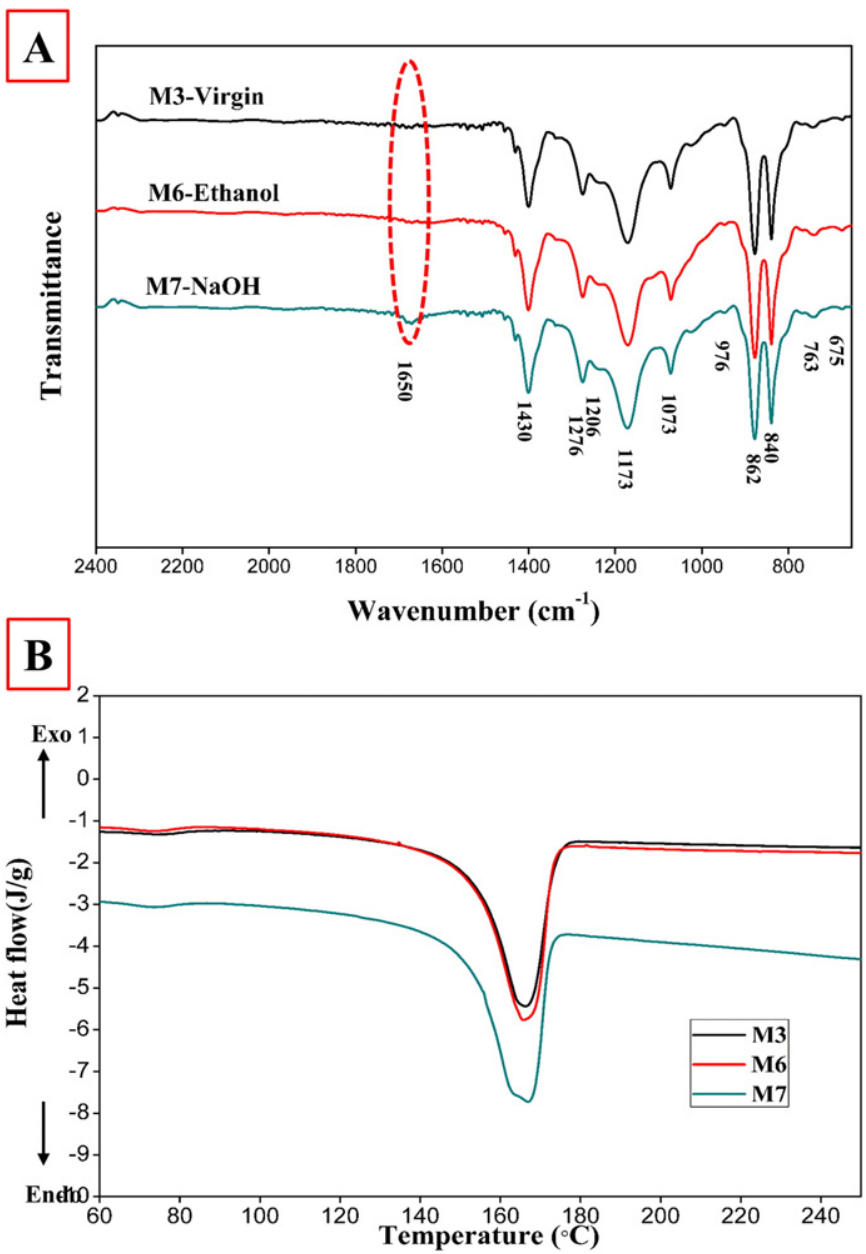

Fig. 7. FTIR spectrums (A) and DSC curves (B) of virgin PVDF-CTFE membrane and the membranes after post-treatment.

process happened when PVDF-CTFE membrane was treated by $\mathrm{NaOH}$ (Fig. 8), which was reported by previously work when PVDF membrane was treated in alkaline condition [37]. The $\mathrm{C}-\mathrm{Cl}$ bond was more vulnerable with dissociation energy $351.8 \mathrm{~kJ} / \mathrm{mol}$ as compared to $451.9 \mathrm{~kJ} / \mathrm{mol}$ of $\mathrm{C}-\mathrm{F}$ bond. So the dehalogenation happened easily at $\mathrm{C}-\mathrm{Cl}$ bond position for PVDF-CTFE even at a mild alkaline condition. However, carbon - carbon triple bonds was not formed as no peak was detected at $2100 \mathrm{~cm}^{-1}$, which was different from Rabuni's work [35] when $\mathrm{NaOH}$ and $\mathrm{KOH}$ were applied to treat PVDF membrane.

The effect of post-treatment toward membrane's thermal properties was also investigated by DSC to measure and compare the melting temperature and crystallinity of virgin and treated membranes. The DSC curves were presented in Fig. 7B, the data of melting temperature and crystallinity were offered in Table 3 . The membrane melting temperature decreased from $166.14{ }^{\circ} \mathrm{C}$ to $163.57{ }^{\circ} \mathrm{C}$ after $\mathrm{NaOH}$ treatment, and the crystallinity also decreased to $55.97 \%$ even the $\beta$ phase content of the membrane showed no significant variation. Meanwhile, the crystallinity also decreased as the effect of PVDF polymorphs was taken into consideration. It means the polymer crystalline structure has been changed by $\mathrm{NaOH}$, which result in the variation in melting temperature and crystallinity. However, the dehalogenation process has not induced the transfer of $\alpha$ and $\beta$ polymorph as the $\beta$ phase content kept the same level after $\mathrm{NaOH}$ treated.

The hydrophobicity of membrane also further affirmed that the $\mathrm{NaOH}$ possessed significantly influence on membrane as the $\mathrm{CA}_{\mathrm{w}}$ decreased from $97.28^{\circ}$ to $82.74^{\circ}$. Topographically, the decrease in hydrophobicity resulted from the decrease in membrane roughness and surface porosity as discussed in Section 3.3. Meanwhile, the dehydrofluorination process 


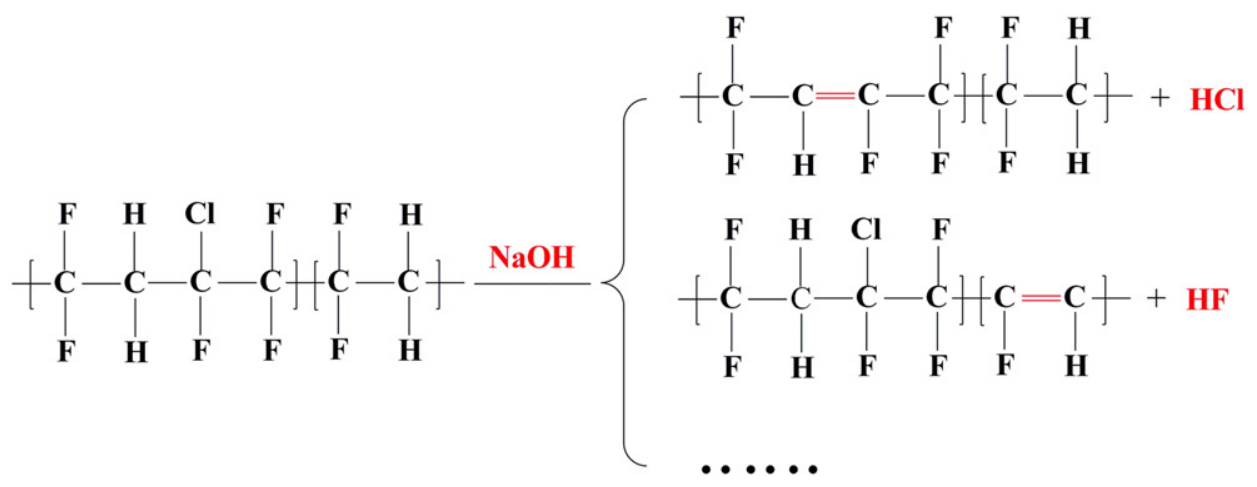

Fig. 8. Dehalogenation process of PVDF-CTFE membrane as treated by $\mathrm{NaOH}$.

was thought to be another reason for lower hydrophobicity as the fluorine content was decreased $[20,50]$.

While for membrane M6, which was treated by ethanol, no significant variation has been detected both for FT-IR and DSC as shown in Fig. 7 and Table 3. Indicating that ethanol has no detectible impacts on polymer chemical structure and membrane thermal and crystalline properties. However, the $\mathrm{CA}_{\mathrm{w}}$ decreased to $92.37^{\circ}$ as shown in Table 3, which was believed to be caused by the membrane surface morphology and the pore structure. As compared to $\mathrm{M} 7$, the variation in $\mathrm{CA}_{\mathrm{w}}$ can be overlooked, which further indicating that ethanol has no significant effect on membrane chemical structure and crystalline property. It was safe to infer that the preventing of membrane partial shrinkage was the main reason for ethanol treatment according to the influence on membranes, which was different from $\mathrm{NaOH}$ treatment where the dehalogenation process was believed to be the main reason.

\subsection{The effect of post-treatment on membrane MD performance}

In general, the performance of MD process has strong correlation to membrane morphology, pore structure, and hydrophobicity. So it can be expected that the post-treatment process has influence on membrane performance due to the variation in membrane morphology and properties. The same DCMD setup was also applied to investigate the performance of the treated membranes and the permeate flux and salt rejection were showed in Fig. 9. It can be found that the permeate flux for both treated membranes increased, $\mathrm{M} 7$ treated by $\mathrm{NaOH}$ showed higher increase to $22.9 \mathrm{~kg} / \mathrm{m}^{2} \cdot \mathrm{h}$ as compared to $20.65 \mathrm{~kg} / \mathrm{m}^{2} \cdot \mathrm{h}$ for the virgin membrane. The increased flux was resulted from the pore enlargement especially for membrane surface, as the overall structure showed no significant variation. As the effect pore passage determine the permeate flux, the larger pore size means the larger passage size. So the flux increased as the number of passage showed little variation. Meanwhile, the decrease of hydrophobicity of M7 was also believed to be another reason. Which also explain the reduction in salt rejection of DCMD test. However, the MD performance was stable during the $6 \mathrm{~h}$ continuous operation, indicating that the post treatment by ethanol and $\mathrm{NaOH}$ in mild condition have modified membrane performance even the modification mechanism of these two solution were different.

\section{Conclusion}

In the present work, hydrophobic membrane was prepared from PVDF-CTFE/LiCl/DMAc/ $\mathrm{H}_{2} \mathrm{O}$ quaternary system by NIPS. The effect of polymer concentration was systematically investigated in terms of membrane formation process, membrane morphology and pore structure, crystalline property, and DCMD desalination performance. It was found that the higher polymer content tend to suppress the macrovoids in cross-section, reduce the pore size, and benefit the crystallization process, so the hydrophobicity and pore interconnectivity were higher. The interconnected surface pore structure also resulted in the increase in surface porosity along with the polymer concentration when it was lower than $12 \%$, while the pore-wane effect of polymer addition would show more influence when further increase the concentration. We also found that the effective pore passage rather than pore size was in strong positive correlation with the permeate flux as the pore interconnectivity also plays an important role during DCMD process. Thus the membrane M3 was found to have a best DCMD performance: permeate flux of $20.65 \mathrm{~kg} / \mathrm{m}^{2} \cdot \mathrm{h}$ with a salt rejection higher than $99.95 \%$.

Ethanol and $\mathrm{NaOH}$ solution were applied as second immersion bath to modify membrane properties and performance. Pore enlargement effects were found for both post-treated membranes, along with the increase in DCMD flux. However, the membrane modification mechanism of two solutions was different. For $\mathrm{NaOH}$, the dehalogenation process was the

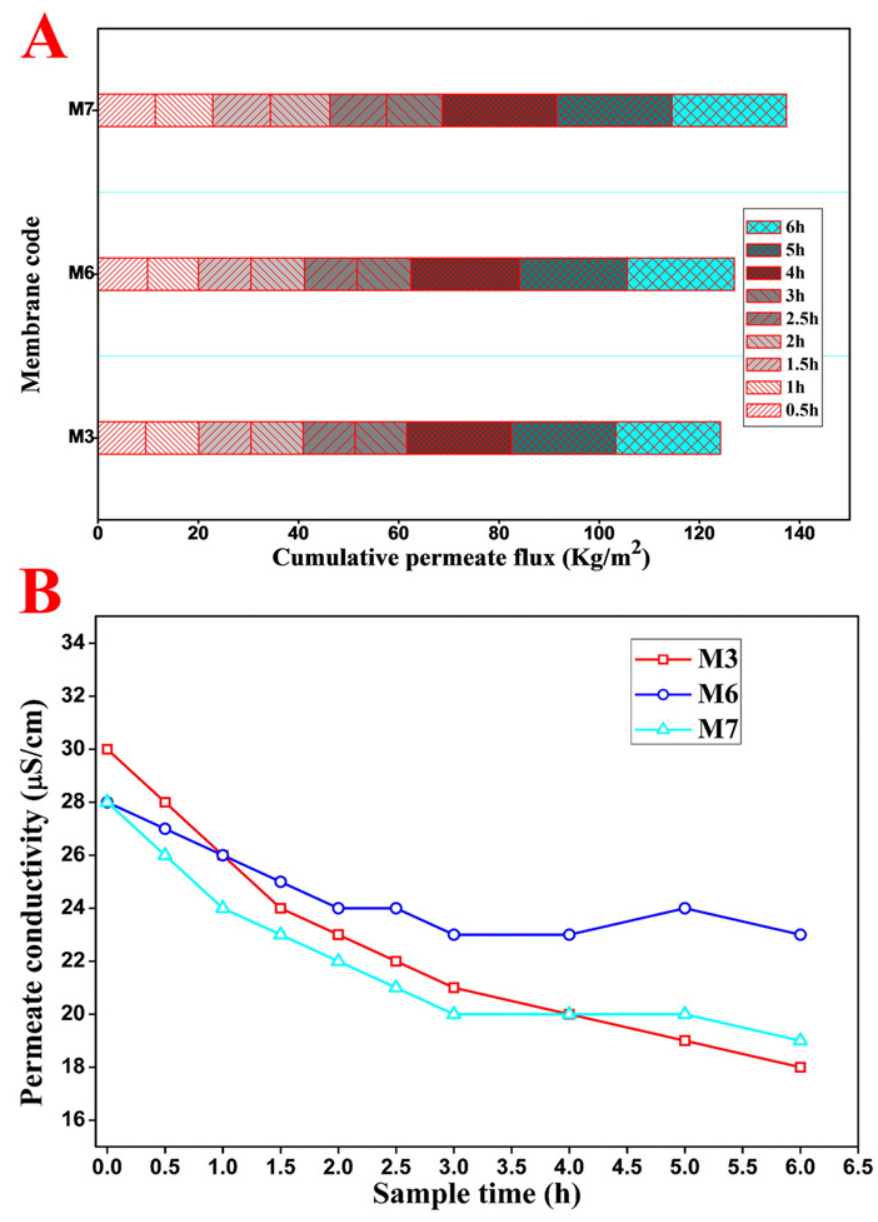

Fig. 9. Permeability of virgin PVDF-CTFE membrane and membranes after post-treatment, A: permeate flux; B: salt rejection. 
most important mechanism for membrane variations. While for ethanol, the pore enlargement effect result from the obstruction of partial shrinkage of nascent membrane was the main mechanism. However, the overall membrane structure of membrane maintained after post-treatment. It was sure that immersion with a second solution bath is a simple method to modify PVDF-CTFE membrane as the flux enhancement without the sacrifice of salt rejection. However, more work should be done to found the optimal modification condition including the type and concentration of second immersion bath, operation condition, and ambient condition, further analysis of modification process was also needed to illuminate the modification mechanism.

\section{Acknowledgements}

This work was supported by the National Natural Science Foundation of China (Grant No. 51378491 and No. 51578533) and the National Key Research and Development Program of China (Grant No. 2016YFC0400501).

\section{References}

[1] E. Drioli, A. Ali, F. Macedonio, Membrane distillation: recent developments and perspectives, Desalination 356 (2015) 56-84.

[2] P. Wang, T.S. Chung, Recent advances in membrane distillation processes: Membrane development, configuration design and application exploring, J. Membr. Sci. 474 (2015) 39-56.

[3] C. Charcosset, I. Limayem, H. Fessi, The membrane emulsification process: a review, J. Chem. Technol. Biotechnol. 79 (2004) 209-218.

[4] M. Gryta, Osmotic MD and other membrane distillation variants, J. Membr. Sci. 246 (2005) 145-156.

[5] G. Jyoti, A. Keshav, J. Anandkumar, Review on pervaporation: theory, membrane performance, and application to intensification of esterification reaction, J. Eng. (2015).

[6] E. Drioli, G. Di Profio, E. Curcio, Progress in membrane crystallization, Curr. Opin. Chem. Eng. 1 (2012) 178-182.

[7] D. Sun, M.Q. Liu, J.H. Guo, J.Y. Zhang, B.B. Li, D.Y. Li, Preparation and characterization of PDMS-PVDF hydrophobic microporous membrane for membrane distillation, Desalination 370 (2015) 63-71.

[8] L. Zhao, X. Lu, C. Wu, Q. Zhang, Flux enhancement in membrane distillation by incorporating AC particles into PVDF polymer matrix, J. Membr. Sci. 500 (2016) 46-54.

[9] N. Ahmad, C. Leo, A. Ahmad, W. Ramli, Membranes with great hydrophobicity: a review on preparation and characterization, Sep. Purif. Rev. 44 (2015) 109-134.

[10] J.E. Efome, D. Rana, T. Matsuura, C.Q. Lan, Enhanced performance of PVDF nanocomposite membrane by nanofiber coating: a membrane for sustainable desalination through MD, Water Res. 89 (2016) 39-49.

[11] X. Yu, L. An, J. Yang, S.T. Tu, J. Yan, $\mathrm{CO}_{2}$ capture using a superhydrophobic ceramic membrane contactor, J. Membr. Sci. 496 (2015) 1-12.

[12] W. Kujawski, J. Kujawa, E. Wierzbowska, S. Cerneaux, M. Bryjak, J. Kujawski, Influence of hydrophobization conditions and ceramic membranes pore size on their properties in vacuum membrane distillation of water-organic solvent mixtures, J. Membr. Sci. 499 (2016) 442-451.

[13] A. Larbot, L. Gazagnes, S. Krajewski, M. Bukowska, W. Kujawski, Water desalination using ceramic membrane distillation, Desalination 168 (2004) 367-372.

[14] G.R. Guillen, Y. Pan, M. Li, E.M. Hoek, Preparation and characterization of membranes formed by nonsolvent induced phase separation: a review, Ind. Eng. Chem. Res. 50 (2011) 3798-3817.

[15] Z. Cui, E. Drioli, Y.M. Lee, Recent progress in fluoropolymers for membranes, Prog. Polym. Sci. 39 (2014) 164-198

[16] L. Zheng, J. Wang, Y. Wei, Y. Zhang, K. Li, Z. Wu, Interconnected PVDF-CTFE hydrophobic membranes for MD desalination: effect of PEGs on phase inversion process, RSC Adv. 6 (2016) 20926-20937.

[17] P. Sukitpaneenit, T.S. Chung, Molecular elucidation of morphology and mechanical properties of PVDF hollow fiber membranes from aspects of phase inversion, crystallization and rheology, J. Membr. Sci. 340 (2009) 192-205.

[18] J. Mulder, Basic Principles of Membrane Technology, Springer science \& business media, 2012

[19] M. Buonomenna, P. Macchi, M. Davoli, E. Drioli, Poly (vinylidene fluoride) membranes by phase inversion: the role the casting and coagulation conditions play in their morphology, crystalline structure and properties, Eur. Polym. J. 43 (2007) 1557-1572.

[20] M.D.C. García-Payo, M. Essalhi, M. Khayet, Effects of PVDF-HFP concentration on membrane distillation performance and structural morphology of hollow fiber membranes, J. Membr. Sci. 347 (2010) 209-219.

[21] N. Ghasem, M. Al-Marzouqi, A. Duidar, Effect of PVDF concentration on the morphology and performance of hollow fiber membrane employed as gas-liquid membrane contactor for $\mathrm{CO}_{2}$ absorption, Sep. Purif. Technol. 98 (2012) 174-185.

[22] C. Feng, B. Shi, G. Li, Y. Wu, Preparation and properties of microporous membrane from poly (vinylidene fluoride-co-tetrafluoroethylene)(F2. 4) for membrane distillation, J. Membr. Sci. 237 (2004) 15-24.
[23] H. Lee, M. Alcoutlabi, O. Toprakci, G. Xu, J.V. Watson, X. Zhang Preparation and characterization of electrospun nanofiber-coated membrane separators for lithium-ion batteries, J. Solid State Electrochem. 18 (2014) 2451-2458.

[24] F. Liu, M.R.M. Abed, K. Li, Hydrophilic modification of P(VDF-co-CTFE) porous membranes, Chem. Eng. Sci. 66 (2011) 27-35.

[25] L. Zheng, Z. Wu, Y. Wei, Y. Zhang, Y. Yuan, J. Wang, Preparation of PVDF-CTFE hydrophobic membranes for MD application: effect of LiCl-based mixed additives, J. Membr. Sci. 506 (2016) 71-85.

[26] A. Idris, I. Ahmed, M.A. Limin, Influence of lithium chloride, lithium bromide and lithium fluoride additives on performance of polyethersulfone membranes and it application in the treatment of palm oil mill effluent, Desalination 250 (2010) 805-809.

[27] A. Mansourizadeh, A.F. Ismail, Effect of $\mathrm{LiCl}$ concentration in the polymer dope on the structure and performance of hydrophobic PVDF hollow fiber membranes for $\mathrm{CO}_{2}$ absorption, Chem. Eng. J. 165 (2010) 980-988.

[28] M.R. Bilad, E. Guillen-Burrieza, M.O. Mavukkandy, F.A. Al Marzooqi, H.A. Arafat Shrinkage, defect and membrane distillation performance of composite PVDF membranes, Desalination 376 (2015) 62-72.

[29] G.D. Kang, Y.M. Cao, Application and modification of poly (vinylidene fluoride)(PVDF) membranes - a review, J. Membr. Sci. 463 (2014) 145-165.

[30] A. Bhattacharya, B. Misra, Grafting: a versatile means to modify polymers: techniques, factors and applications, Prog. Polym. Sci. 29 (2004) 767-814

[31] J.J. Qin, J. Gu, T.S. Chung, Effect of wet and dry-jet wet spinning on the shear-induced orientation during the formation of ultrafiltration hollow fiber membranes, J. Membr. Sci. 182 (2001) 57-75.

[32] F. Tasselli, J. Jansen, F. Sidari, E. Drioli, Morphology and transport property control of modified poly (ether ether ketone)(PEEKWC) hollow fiber membranes prepared from PEEKWC/PVP blends: influence of the relative humidity in the air gap, J. Membr. Sci. 255 (2005) 13-22.

[33] M. Khayet, M. García-Payo, F. Qusay, K. Khulbe, C. Feng, T. Matsuura, Effects of gas gap type on structural morphology and performance of hollow fibers, J. Membr. Sci. 311 (2008) 259-269.

[34] N.A. Hashim, Y. Liu, K. Li, Stability of PVDF hollow fibre membranes in sodium hydroxide aqueous solution, Chem. Eng. Sci. 66 (2011) 1565-1575.

[35] M. Rabuni, N.N. Sulaiman, M. Aroua, N.A. Hashim, Effects of alkaline environments at mild conditions on the stability of PVDF membrane: an experimental study, Ind. Eng. Chem. Res. 52 (2013) 15874-15882.

[36] M. Rabuni, N.N. Sulaiman, M. Aroua, C.Y. Chee, N.A. Hashim, Impact of in situ physical and chemical cleaning on PVDF membrane properties and performances, Chem Eng. Sci. 122 (2015) 426-435.

[37] N.A. Samsure, N.A. Hashim, N.M.N. Sulaiman, C.Y. Chee, Alkaline etching treatment of PVDF membrane for water filtration, RSC Adv. 6 (2016) 22153-22160.

[38] D. Hou, G. Dai, J. Wang, H. Fan, L. Zhang, Z. Luan, Preparation and characterization of PVDF/nonwoven fabric flat-sheet composite membranes for desalination through direct contact membrane distillation, Sep. Purif. Technol. 101 (2012) 1-10.

39] F.A. AlMarzooqi, M. Bilad, B. Mansoor, H.A. Arafat, A comparative study of image analysis and porometry techniques for characterization of porous membranes, J. Mater. Sci. 51 (2016) 2017-2032.

[40] S.Z. Abdullah, P.R. Bérubé, D.J. Horne, SEM imaging of membranes: importance of sample preparation and imaging parameters, J. Membr. Sci. 463 (2014) 113-125.

[41] S. Banerjee, R. Yang, C.E. Courchene, T.E. Conners, Scanning electron microscopy measurements of the surface roughness of paper, Ind. Eng. Chem. Res. 48 (2009) 4322-4325.

[42] R. Gregorio Jr., M. Cestari, Effect of crystallization temperature on the crystalline phase content and morphology of poly (vinylidene fluoride), J. Polym. Sci. B Polym. Phys. 32 (1994) 859-870.

[43] V.F. Cardoso, G. Botelho, S. Lanceros-Méndez, Nonsolvent induced phase separation preparation of poly (vinylidene fluoride-co-chlorotrifluoroethylene) membranes with tailored morphology, piezoelectric phase content and mechanical properties, Mater. Des. 88 (2015) 390-397.

[44] R.E. Sousa, J.C.C. Ferreira, C. Costa, A.V. Machado, M.M. Silva, S. Lanceros-Mendez Tailoring poly (vinylidene fluoride-co-chlorotrifluoroethylene) microstructure and physicochemical properties by exploring its binary phase diagram with dimethylformamide, J. Polym. Sci. B Polym. Phys. 53 (2015) 761-773.

[45] L.D. Tijing, Y.C. Woo, W.-G. Shim, T. He, J.S. Choi, S.H. Kim, H.K. Shon, Superhydrophobic nanofiber membrane containing carbon nanotubes for high-performance direct contact membrane distillation, J. Membr. Sci. 502 (2016) 158-170.

[46] M. Rafat, D. De, K. Khulbe, T. Nguyen, T. Matsuura, Surface characterization of hollow fiber membranes used in artificial kidney, J. Appl. Polym. Sci. 101 (2006) 4386-4400.

[47] Q. Li, Z.L. Xu, M. Liu, Preparation and characterization of PVDF microporous membrane with highly hydrophobic surface, Polym. Adv. Technol. 22 (2011) 520-531.

[48] Z. Wang, M. Elimelech, S. Lin, Environmental applications of interfacial materials with special wettability, Environ. Sci. Technol. 50 (2016) 2132-2150.

[49] G. Rácz, S. Kerker, O. Schmitz, B. Schnabel, Z. Kovacs, G. Vatai, M. Ebrahimi, P. Czermak, Experimental determination of liquid entry pressure (LEP) in vacuum membrane distillation for oily wastewaters, Membrane Water Treatment 6 (2015) 237-249.

[50] S. Fadhil, T. Marino, H.F. Makki, Q.F. Alsalhy, S. Blefari, F. Macedonio, E. Di Nicolò, L. Giorno, E. Drioli, A. Figoli, Novel PVDF-HFP flat sheet membranes prepared by triethyl phosphate (TEP) solvent for direct contact membrane distillation, Chem. Eng. Process. Process Intensif. (2016). 